\title{
WatchBP Home A for Opportunistically Detecting Atrial Fibrillation During Diagnosis and Monitoring of Hypertension: A NICE Medical Technology Guidance
}

\author{
Iain Willits $\cdot$ Kim Keltie $\cdot$ Joyce Craig $\cdot$ \\ Andrew Sims
}

Published online: 25 March 2014

(c) The Author(s) 2014. This article is published with open access at Springerlink.com

\begin{abstract}
The Microlife ${ }^{\circledR}$ 'WatchBP Home A' oscillometric blood pressure monitor detects irregular pulse, suggestive of atrial fibrillation (AF). Early detection of AF can prevent thromboembolic stroke via anticoagulation therapy. The device was considered by the Medical Technologies Evaluation Programme of the UK National Institute for Health and Care Excellence (NICE). The sponsor (Microlife) identified 10 studies. These were reviewed by an External Assessment Centre (EAC) which considered three relevant to the decision problem, including one which found the device detected AF more accurately (sensitivity $96.8 \%$, specificity $88.8 \%$ ) than pulse palpation $(87.2,81.3 \%)$. The EAC concluded the technology had potential to improve detection of AF, but the three studies had uncertain external validity. From a costconsequence model with a 1-year timeframe, the sponsor calculated the device would reduce electrocardiogram (ECG) referrals and prevent strokes, but incur anticoagulation therapy costs, with net NHS savings of $£ 11.6$ million and prevention of 221 strokes, annually. The EAC criticised the model for its limited time horizon, and its consideration of symptomatic AF patients who were outside the scope issued by NICE. The EAC applied a de novo Markov model, with a 10-year timeframe. The per use saving was calculated as $£ 2.98$ for asymptomatic patients aged $65-74$ years and $£ 4.26$ for those aged $75-84$ years,
\end{abstract}

I. Willits $\cdot$ K. Keltie $\cdot$ A. Sims $(\bowtie)$

Newcastle upon Tyne Hospitals NHS Foundation Trust, Freeman Hospital, Freeman Road, Newcastle upon Tyne NE7 7DN, UK e-mail: andrew.sims@nuth.nhs.uk

J. Craig

York Health Economics Consortium, University of York, Market Square, Vanbrugh Way, Heslington, York,

North Yorkshire YO10 5HN, UK with the prevention of 53-117 nonfatal and 28-65 fatal strokes per 100,000 people screened. Following consideration by the NICE Medical Technologies Advisory Committee, NICE judged that the case for adoption was supported by the evidence (Medical Technologies Guidance 13; MTG13).

\section{Key Points for Decision Makers}

The available evidence suggests that the device reliably detects atrial fibrillation and may increase the rate of detection when used in primary care during hypertension screening. People suspected of having atrial fibrillation after use of 'WatchBP Home A' should have an electrocardiogram (ECG) in line with NICE clinical guideline 36, Atrial fibrillation.

Use of WatchBP Home A in primary care is associated with estimated overall cost savings per person, ranging from $£ 2.98$ for those aged between 65 and 74 years to $£ 4.26$ for those aged 75 years and over.

Cost analyses did not support the use of the device by patients in their homes.

\section{Introduction}

The National Institute for Health and Care Excellence (NICE) provides evidence-based guidance for the National Health Service (NHS) in England and Wales with the aim of improving clinical outcomes for patients, as well as 
delivering efficiency gains in the use of health service resources. The NICE Medical Technologies Evaluation Programme (MTEP) has a specific aim of evaluating and, where appropriate, encouraging the adoption of, new and innovative medical devices into the NHS [1].

The NICE Medical Technologies Advisory Committee (MTAC) comprises up to 25 members who have a range of expertise and includes clinicians, health economists, commissioners and lay people. The primary function of MTAC is to select and route technologies on which guidance should be produced, and to develop guidance on selected technologies. The sponsor (usually the manufacturer of the device) is asked to submit clinical and cost evidence according to a scope issued by NICE [2]. The sponsor's submission is independently critiqued by an External Assessment Centre (EAC) and a report is produced. Thus, the production of guidance on medical devices is influenced by the sponsor (who provide the evidence), the EAC (who evaluate the evidence and, if necessary, conduct further modelling) and MTAC (who consider the evaluated evidence and make recommendations).

The 'WatchBP Home A', manufactured by the sponsor Microlife $^{\circledR}$, is an automated blood pressure (BP) monitor for use in home or primary care, which also includes an algorithm for assessing irregular heartbeat. In January 2013, NICE published final guidance (MTG13) on this device [3]. This article presents a summary of the EAC report and the development of the NICE guidance. It is one of a series of NICE Medical Technology Guidance summaries being published in Applied Health Economics and Health Policy $[1,4,5]$. The EAC involved in the evaluation was the Newcastle upon Tyne Hospitals NHS Foundation Trust and York Health Economics Consortium (NUTH/ YHEC) partnership. Documentation of the supporting evidence and process can be found on the NICE website [6].

\section{Background to the Conditions and Device}

Hypertension (high BP) is one of the leading causes of premature morbidity and mortality in the UK, and is a major risk factor for stroke, myocardial infarction, heart failure, chronic kidney disease, peripheral vascular disease, cognitive decline and premature death [7]. The risks of death from stroke and from ischaemic heart disease or other vascular causes approximately double with each $20 \mathrm{mmHg}$ increase in systolic BP [8]. Hypertension is also the primary risk factor for atrial fibrillation (AF) [9]. It is estimated that about a quarter of the UK population are hypertensive, with more than half of these being over 60 years of age (also around the age when the risk of AF significantly increases) [10]. Hypertension, once diagnosed, can usually be adequately controlled through lifestyle changes and pharmacotherapy, which in turn reduces the likelihood of serious cardiovascular events. BP is usually measured in primary care, increasingly by using an electronic oscillometric BP monitor.

Lévy et al. [11] define AF as "an atrial tachyarrhythmia characterised by predominantly uncoordinated atrial activation with consequent deterioration of atrial mechanical function". It is classified into three types depending on how long episodes last: paroxysmal (multiple episodes that cease within 7 days without treatment); persistent (episodes lasting longer than 7 days, or less when treated); or permanent (continuous AF which has occurred for more than 1 year) [12]. Additionally, AF is frequently asymptomatic and is often first detected incidentally [13].

According to the 2012 Quality and Outcomes Framework (QOF) database, 978,019 people were registered as having $\mathrm{AF}$ in the UK, which is about $1.5 \%$ of the population [14]. The prevalence of AF advances with age, roughly doubling with each advancing decade [15]. The annual incidence of $\mathrm{AF}$ in people aged over 65 years was estimated as $1.04 \%$ in a sample of 4,936 control subjects [16].

AF predisposes to thrombus formation, causing sufferers to have a 5-fold increased risk of stroke and thromboembolism [17]. Cardiac output may be compromised regardless of ventricular function, and AF can lead to structural heart disease and can precipitate critical cardiac ischaemia. Overall, AF is associated with an odds ratio (OR) for death of 1.5 in men and 1.9 in women, with most of the excess mortality occurring soon after the diagnosis of AF [18]. For AF that cannot be reversed through pharmacological or electric mediated cardioversion, the main treatment option is antiplatelet or anticoagulation drug therapy to prevent thromboembolic events, in particular stroke [12].

Thus, both hypertension and AF are major risk factors for serious cardiovascular events, and both have treatment options once diagnosed. There is good evidence that opportunistic screening for AF using manual palpation in primary care is cost effective $[16,19]$ and screening for hypertension forms part of the NHS health check programme [20], although there is no formal screening programme in the UK for the diagnosis of $\mathrm{AF}$ in the population. The WatchBP Home A is a conventional automated oscillometric BP monitor which also detects irregular heart rhythms, which are most commonly due to AF. The WatchBP Home A may be considered as a replacement for manual pulse palpation in the clinic or in the home. The sponsor's case for adoption of the WatchBP Home A was that the device shows promise in having the potential to incidentally detect AF during the routine measurement of BP, with no additional time or cost considerations. Thus, the dual functionality of the device might lead to the early detection and diagnosis of $\mathrm{AF}$ in 
asymptomatic populations, allowing for early management and prevention of thromboembolic disease, particularly stroke. The committee selected the device for consideration as a dual function device for the diagnosis and monitoring of hypertension and as a tool for the opportunistic detection of $\mathrm{AF}$ in high-risk groups.

\section{Decision Problem (Scope)}

\subsection{Population}

The target population described in the scope was people with suspected or existing hypertension or those who are being screened for hypertension, and, within this group, those people in whom AF is present but undetected. The population described refers to people with asymptomatic $\mathrm{AF}$ in whom incidental detection of AF might occur; people who are symptomatic of AF and are consulting with their GPs for that reason were excluded, as the WatchBP Home $\mathrm{A}$ is not intended to be used to diagnose AF.

\subsection{Comparator (Current Practice)}

Two clinical guidelines have been published by NICE that are directly relevant to the decision problem: Atrial Fibrillation (CG36) [12] and Hypertension (CG127) [10]. The latter is of greater relevance to the detection of AF during the routine measurement of BP. These guidelines recommend that irregular pulse should be screened for during the routine measurement of BP in the office or clinic (this is mainly because irregular pulse can adversely affect the diagnostic accuracy of BP measurement devices). If an electronic oscillometric BP monitor is used, this should be done by using manual palpation of the ulnar or radial pulse. If an irregular pulse is detected, a manual measurement of BP should be performed, preferably using a non-mercury sphygmomanometer with auscultation of the brachial artery, and the patient should be referred for a 12-lead electrocardiogram (ECG), which is used to definitively diagnose AF or an alternative diagnosis (i.e., ECG is the gold standard) [16].

NICE clinical guidelines for AF recommend targeted or opportunistic screening using pulse palpation for $\mathrm{AF}$ in patients who have symptoms of the condition or are at particularly high risk. The associated symptoms of AF include breathlessness, dyspnoea, palpitations, syncope/ dizziness or chest discomfort [12]. People described in this population are out of scope of the decision problem, as they would not normally be indicated for assessment of AF with the WatchBP Home A, which is intended primarily for measurement of BP rather than as a screening or diagnostic tool for $\mathrm{AF}$.

\subsection{Intervention (the WatchBP Home A)}

The intervention, as described by the scope issued by NICE, was the WatchBP Home A. In their submission, the sponsor focused on the novel AF detection aspect of the device rather than its BP measurement capability, for which it was validated [21]. As pulse palpation to detect pulse irregularity is recommended before BP measurement [10], a direct comparison of the diagnostic accuracy of pulse palpation with the WatchBP Home A was most relevant to the decision problem.

The WatchBP Home A may be used in either a clinical setting (i.e., GP or nurse's office) or in a home setting. In the latter case, the device would be used for the diagnosis of hypertension if ambulatory BP measurement was not suitable, or for the monitoring of hypertension following diagnosis (e.g., to assist with antihypertensive drug titration).

\subsection{Outcomes}

As the WatchBP Home $\mathrm{A}$ is a diagnostic rather than an interventional device, its use will influence subsequent clinical pathways. The outcomes specified in the scope were: diagnostic accuracy for hypertension; diagnostic accuracy for AF; incidence of AF-related stroke in patients found to have AF; reduced mortality from AF-related stroke (following antiplatelet or anticoagulation therapy); reduced disability from AF-related stroke; and devicerelated adverse events.

\section{Review of Clinical and Economic Evidence}

The sponsor submitted clinical and economic evidence according to a scope issued by NICE [2]. The economic evidence included a de novo cost-consequence analysis. The EAC critically appraised the submission and carried out additional analyses to evaluate the outcomes identified in the scope.

\subsection{Clinical Effectiveness Evidence}

\subsubsection{Sponsor's Review of Clinical Effectiveness Evidence}

The sponsor performed a literature search and identified and presented a total of ten studies that they considered were relevant to the decision problem. The EAC considered five were relevant to the decision problem (i.e., within scope); these were four published studies [22-25] and one study that was awaiting publication at the time of assessment and has since been published [26]. Five studies were not fully appraised by the EAC as they were BP measurement validation studies or measurement of BP was their sole outcome, 
and they were not used by the sponsor in their evaluation of the device. Of these excluded studies, three were peer reviewed and published [21, 27, 28], one was a conference abstract [29], and an additional, unpublished, randomized controlled trial (RCT) that was potentially highly relevant to the decision problem was in the process of patient recruitment, but no results were available [30].

Of the five studies that were available and relevant to the decision problem, three were in a secondary-care clinical setting [22, 24, 25] and two (one published [23] and one unpublished at the assessment [26]) were based in a home setting. The studies in a home setting, although within scope, were not used for further analysis by the EAC as this scenario was not explored further by the sponsor, and the only published study [23] was an uncontrolled case series with a population not within the scope of the decision problem (people with a previous history of AF). The unpublished study included patients with AF and used a non-standard comparator (ECG events monitor) [26]. This left three studies $[22,24,25]$ that were potentially useful to inform the clinical effectiveness of the WatchBP Home A as well as to support the assumptions of the economic analysis.

Descriptions of the relevant studies, and an additional study that was identified by the sponsor and used to supply data concerning the comparator (pulse palpation) [16], are given in Table 1. These were cross-sectional diagnostic studies, with the diagnostic accuracy of the AF detection algorithm of the WatchBP Home A compared with 12-lead ECG as their main outcome. Overall, these studies indicated that the sensitivity of the AF detection algorithm was 93-100\% [22, 24], specificity was 69-91\% [22, 24], positive predictive value (PPV) was $68 \%$, and negative predictive value (NPV) was $98 \%$ [25] (Table 2).

The sponsor critically appraised the literature using a checklist, but did not attempt to place the studies within the context of the decision problem. In particular, the sponsor did not discuss how limitations in the external validity of the studies might impact on their generalisability to UK primary healthcare practice.

\subsubsection{Critique of Clinical Effectiveness Evidence}

The EAC considered that only three of the provided studies were relevant to the decision problem. None of these studies used the WatchBP Home A as the intervention, although the sponsor confirmed that all used an algorithm equivalent to that which is embedded in the device.

The three cross-sectional diagnostic studies [22, 24, 25] were considered by the EAC to be appropriate to assess the diagnostic accuracy of the device (that is, they were of a suitable design to assess how accurately the device identifies people with irregular pulse and possible $\mathrm{AF}$, and how well the device excludes people who do not have an irregular pulse). All the studies used 12-lead ECG as the reference standard, which is widely regarded as the gold standard test for the diagnosis of $\mathrm{AF}$, and, because it uses an entirely different mechanism to detect $\mathrm{AF}$, it is not subject to incorporation bias [31]. The EAC critically appraised these studies using methodology adopted from the Critical Appraisal Skills Programme [32], and considered that they had adequate internal validity.

The EAC considered the external validity of the selected studies and the extent to which they related to the primarycare setting of the NHS of England and Wales. It identified specific areas where the population, intervention and comparator used in the studies differed to those described in the scope. Briefly, the populations described in the studies were recruited from secondary care in the USA and Greece, lending them susceptible to referral and spectrum bias [33]. The greater prevalence of AF in these populations would be expected to significantly impact on the PPV and NPV recorded by the device [34]. The intervention used in the studies was not specifically the WatchBP Home A device, and the devices used different modes to the WatchBP Home A; for instance, in the number of readings required to deliver a positive 'detection' of AF. Finally, the comparator used in the studies, although appropriate as a gold standard to evaluate diagnostic accuracy, was not that of the scope, which was pulse palpation.

Because analysis of the appropriate comparator, pulse palpation, was critical to answer the decision problem, the EAC undertook a brief literature search to find relevant studies that might address this issue. As no head-to-head studies of the WatchBP Home A (or equivalent device) and pulse palpation were identified, the EAC made an indirect comparison using data derived from the SAFE (Screening for Atrial Fibrillation in the Elderly) study [16], which was considered to be of highest methodological quality and have greatest external validity. The SAFE study was a large $(n=14,802)$, multicentre, pragmatic RCT commissioned by the NHS Research and Development Health Technology Assessment (HTA) Programme. It investigated the effectiveness and cost effectiveness of an opportunistic strategy to screen for AF using pulse palpation (followed by confirmatory 12-lead ECG) with systematic screening with nurse- or GP-led ECG (followed by confirmatory 12-lead ECG) in an elderly population. In addition, there was a control arm who received neither screening intervention. The opportunistic strategy proved to be most cost effective. The diagnostic parameters reported concerning pulse palpation were a sensitivity of $87.2 \%$, a specificity of $81.3 \%$, a PPV of $30.1 \%$, and an NPV of $98.6 \%$ when comparing GP- or nurse-led pulse palpation with 12-lead ECG [16]. The results of this study, together with those from the sponsor-identified studies on the Watch BP Home A, are presented in Table 2. These data were used in subsequent economic analysis. 


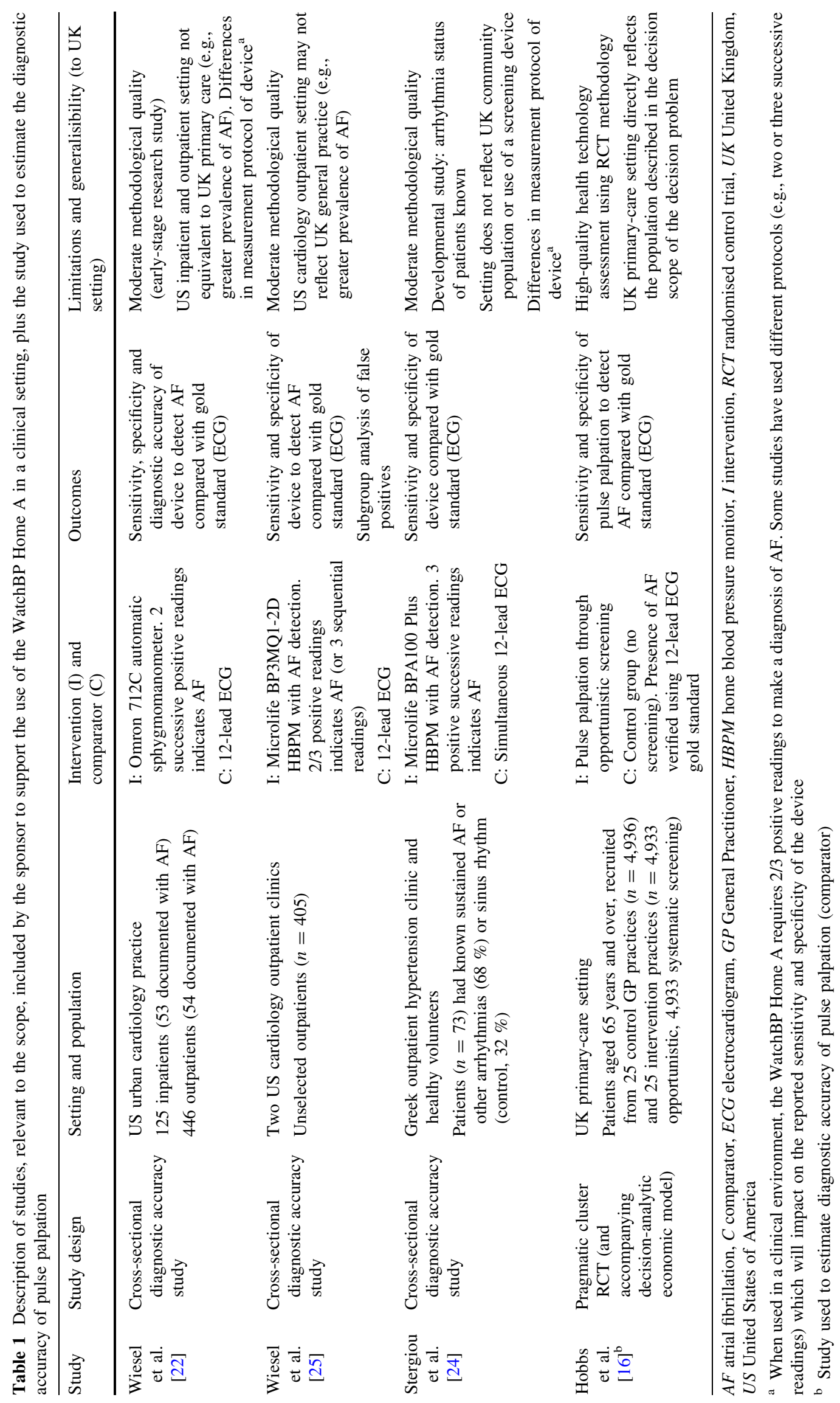


Table 2 Results of included studies assessing the diagnostic accuracy of the WatchBP Home A [22, 24, 25] and pulse palpation [16, 36]

\begin{tabular}{|c|c|c|c|c|}
\hline Study & Participants & $\begin{array}{l}\text { Sensitivity (with } 95 \% \text { CI } \\
\text { where available) }\end{array}$ & $\begin{array}{l}\text { Specificity (with } 95 \% \text { CI } \\
\text { where available) }\end{array}$ & Other reported outcomes \\
\hline $\begin{array}{l}\text { Wiesel et al. } \\
{[22]^{\mathrm{a}}}\end{array}$ & $\begin{array}{l}446 \text { unselected cardiology } \\
\text { outpatients }\end{array}$ & $\begin{array}{l}1 \text { reading: } 100 \%^{\mathrm{b}} \\
2 \text { readings: } 100 \%\end{array}$ & $\begin{array}{l}1 \text { reading: } 84 \% \\
2 \text { readings: } 91 \%\end{array}$ & Diagnostic accuracy $92 \%$ \\
\hline $\begin{array}{l}\text { Wiesel et al. } \\
{[25]^{\mathrm{b}}}\end{array}$ & $\begin{array}{l}405 \text { unselected cardiology } \\
\text { outpatients }\end{array}$ & $\begin{array}{l}1 \text { reading: } 95.3 \% \\
\text { (92.8-97.6) } \\
3 \text { sequential readings: } \\
96.8 \%(91-99)\end{array}$ & $\begin{array}{l}1 \text { reading: } 86.4 \% \\
(84.3-88.7) \\
3 \text { sequential readings: } \\
88.8 \%(85-92)\end{array}$ & $\begin{array}{l}1 \text { reading: PPV } 67.7 \% \text {, } \\
\text { NPV } 98.4 \% \\
\text { Subgroup analysis of false } \\
\text { negatives }\end{array}$ \\
\hline $\begin{array}{l}\text { Stergiou et al. } \\
{[24]^{\mathrm{a}}}\end{array}$ & $\begin{array}{l}73 \text { outpatients and healthy } \\
\text { volunteers (AF status already } \\
\text { known) }\end{array}$ & $\begin{array}{l}1 \text { reading: } 93 \%(74-99) \\
2 \text { readings: } 100 \% \\
(84-100) \\
2 \text { out of } 3 \text { readings: } 100 \% \\
(84-100) \\
1 \text { out of } 3 \text { readings: } 100 \% \\
(84-100)\end{array}$ & $\begin{array}{l}1 \text { reading: } 89 \%(76-96) \\
2 \text { readings: } 76 \%(60-87) \\
2 \text { out of } 3 \text { readings: } 89 \% \\
(75-96) \\
1 \text { out of } 3 \text { readings: } 69 \% \\
(53-81)\end{array}$ & $\begin{array}{l}1 \text { reading: Kappa } 0.80 \\
(0.65-0.94) \\
2 \text { readings: Kappa } 0.70 \\
(0.54-0.85) \\
2 \text { out of } 3 \text { readings: Kappa } \\
0.86(0.74-0.98) \\
1 \text { out of } 3 \text { readings: Kappa } \\
0.62(0.46-0.79)\end{array}$ \\
\hline $\begin{array}{l}\text { Hobbs et al. } \\
{[16]^{\mathrm{b}}}\end{array}$ & $\begin{array}{l}2,592 \text { subjects ( }>65 \text { years) in UK } \\
\text { primary care (from systematic } \\
\text { screening arm of RCT) }\end{array}$ & $87.2 \%(82.1-91.1)$ & $81.3 \%(79.7-82.8)$ & $\begin{array}{l}\text { PPV } 30.1 \%(26.7-33.8) \\
\text { NPV } 98.6 \%(97.9-99.0)\end{array}$ \\
\hline $\begin{array}{l}\text { Morgan and } \\
\text { Mant [36] }]^{\mathrm{a}, \mathrm{c}}\end{array}$ & $\begin{array}{l}\text { RCT. } 1,099 \text { subjects ( }>65 \text { years) } \\
\text { in } 4 \text { UK GP practices (from } \\
\text { systematic screening arm of } \\
\text { RCT) }\end{array}$ & $91 \%(82-97)^{\mathrm{c}}$ & $74 \%(72-77)^{\mathrm{c}}$ & $\begin{array}{l}\text { PPV } 19 \%(15-23) \\
\text { NPV } 99 \%(98-100)\end{array}$ \\
\hline
\end{tabular}

$A F$ atrial fibrillation, $C I$ confidence interval, $E C G$ electrocardiogram, $G P$ General Practitioner, $N P V$ negative predictive value, $P P V$ positive predictive value, $R C T$ randomised control trial, $U K$ United Kingdom

${ }^{a}$ Study not selected for economic analysis because authors developed a threshold irregularity index to compare accuracy of the device (i.e., sensitivity fixed at $100 \%$ ); AF status of patients already known; comparator used was not gold standard (ECG rhythm strip rather than 12-lead ECG)

b Study selected as most appropriate to inform the critique of the economic model

c Nurse-led pulse palpation

\subsection{Economic Evidence}

\subsubsection{Sponsor's Economic Submission}

The sponsor performed a basic literature search which did not identify any economic studies relevant to the decision problem (i.e., they cited no studies which used the WatchBP Home A device). The sponsor developed a de novo economic model using a cost-consequence design [35], taken from the perspective of the NHS and Personal Social Services (PSS), with a 1-year timeframe. This was constructed using an executable Microsoft Excel spreadsheet. The year of valuation was 2011. In the model, a simulated cohort of patients who were symptomatic of AF underwent screening for AF using either the WatchBP Home A device (intervention) or pulse palpation (comparator). If AF was detected, it would be confirmed with 12-lead ECG and be managed appropriately with anticoagulation or antiplatelet therapy. The differences in sensitivity and specificity between the intervention and comparator meant that there were different proportions of true positives (TPs), false positives (FPs), true negatives (TNs), and false negatives (FNs) for the intervention and comparator groups. Each diagnostic classification was associated with a corresponding clinical consequence; thus, for instance, patients who were classed as TP had AF and were appropriately managed; patients who were FP did not have AF but incurred a charge for an unnecessary ECG; patients who were $\mathrm{TN}$ were correctly excluded from further management; and patients who were $\mathrm{FN}$ were wrongly excluded as not having AF, and were therefore not treated.

Costs to the healthcare system arose from money spent on ECGs, anticoagulation, adverse effects of anticoagulation (limited in the model to gastrointestinal bleeding) and management of stroke. The device itself was not considered to incur a cost, as it was reasoned an alternative BP monitor would be required, and the incremental cost of the WatchBP Home A compared with other oscillometric BP monitors was relatively small. Pulse palpation was assumed to have a time cost of 1 minute, consistent with the SAFE study [16]. The sponsor derived estimates of diagnostic accuracy of the WatchBP Home A from the 
Table 3 Transition parameters and cost values used in the sponsor's economic model. The year of valuation was 2011

\begin{tabular}{|c|c|c|}
\hline Parameter & Value & Comment \\
\hline Prevalence of AF & $4.4 \%$ & $\begin{array}{l}\text { The sponsor calculated this value using an incidence } \\
\text { of } 0.175 \% \text { per year [37], the size of the UK } \\
\text { population and from the sensitivity and specificity } \\
\text { of pulse palpation, estimated from the SAFE study } \\
\text { [16]. Direct estimates of prevalence have been } \\
\text { reported in many studies, including } 1.28 \% \text { for the } \\
\text { general population [37] and } 7.9 \% \text { in over } 65 \text {-year- } \\
\text { olds [44] }\end{array}$ \\
\hline $\begin{array}{l}\text { Probability starting anticoagulant drugs } \\
\text { (e.g., warfarin) }\end{array}$ & $56 \%$ & $\begin{array}{l}\text { Not all AF patients suitable for anticoagulation due } \\
\text { to risk/benefit ratio [37] }\end{array}$ \\
\hline $\begin{array}{l}\text { Probability starting antiplatelets (e.g., } \\
\text { aspirin) }\end{array}$ & $32 \%$ & $\begin{array}{l}\text { The source cited by the sponsor [37] gives this } \\
\text { probability as } 34 \% \text {. Not all AF patients suitable } \\
\text { for antiplatelets due to risk/benefit ratio [37] }\end{array}$ \\
\hline $\begin{array}{l}\text { Absolute risk reduction of having a stroke } \\
\text { if on anticoagulants }\end{array}$ & $4.3 \%$ & $\begin{array}{l}\text { Average absolute risk reduction (all risk categories) } \\
\text { [37]. From the SAFE study [16], Table 5, the } \\
\text { absolute risk reduction for stroke is } 3.3 \%\end{array}$ \\
\hline $\begin{array}{l}\text { Absolute risk reduction of having stroke if } \\
\text { on antiplatelets }\end{array}$ & $0.9 \%$ & $\begin{array}{l}\text { Average absolute risk reduction (all risk categories) } \\
\text { [37]. From the SAFE study [16], Table 5, the } \\
\text { absolute risk reduction for stroke is } 1.1 \%\end{array}$ \\
\hline Probability of minor bleed (on treatment) & $15.8 \%$ & Definition of minor and major bleeds not stated [37] \\
\hline Probability of major bleed (on treatment) & $2.4 \%$ & Definition of major and minor bleeds not stated [37] \\
\hline Cost & Value $^{\mathrm{a}}$ & \\
\hline $\begin{array}{l}\text { Capital costs of WatchBP Home A } \\
\text { and pulse palpation }\end{array}$ & $\begin{array}{l}\text { Negligible for WatchBP Home A, } \\
\text { nil for pulse palpation }\end{array}$ & $\begin{array}{l}\text { Cost of purchase of WatchBP Home A } £ 75.00 \\
\text { (provided by sponsor). Incremental cost of use } \\
\text { of WatchBP Home A over 5-year lifetime } \\
\text { less than } £ 0.01\end{array}$ \\
\hline $\begin{array}{l}\text { Time cost of WatchBP Home A } \\
\text { and pulse palpation }\end{array}$ & $\begin{array}{l}\text { WatchBP Home A nil, Pulse } \\
\text { palpation } £ 2.32\end{array}$ & $\begin{array}{l}\text { Value derived from SAFE study. EAC considered } \\
\text { this differential was not credible considering time } \\
\text { for recommended three measurements using } \\
\text { WatchBP Home A [16] }\end{array}$ \\
\hline ECG (referral) & $£ 36.03$ & $\begin{array}{l}\text { Taken from NHS reference costs, but likely to be } \\
\text { an overestimate }{ }^{\text {b }} \text {, especially if practices operate } \\
\text { their own ECGs [45] or [37] }\end{array}$ \\
\hline $\begin{array}{l}\text { Cost of warfarin therapy (per } \\
\text { patient per year) }\end{array}$ & $£ 489$ & {$[37]$} \\
\hline $\begin{array}{l}\text { Cost of aspirin therapy (per patient } \\
\text { per year) }\end{array}$ & Negligible & $\begin{array}{l}\text { Estimated as } £ 0.09 \text { per patient per day [46], } \\
\text { or } £ 32.85 / \text { year }\end{array}$ \\
\hline Cost of minor adverse effects & $£ 111$ & {$[37]$} \\
\hline Cost of major adverse effects & $£ 1,998$ & {$[37]$} \\
\hline Savings from strokes prevented & $£ 9,906$ & $\begin{array}{l}\text { The cost of stroke is a highly uncertain and } \\
\text { contentious issue. This estimate is taken from } \\
\text { the perspective of the NHS and PSS [37] }\end{array}$ \\
\hline
\end{tabular}

$A F$ atrial fibrillation, EAC External Assessment Centre, ECG electrocardiogram, NHS National Health Service, PSS Personal and Social Services, $S A F E$ Screening for Atrial Fibrillation in the Elderly, UK United Kingdom

${ }^{\text {a }}$ All values were adjusted for inflation at the rate of $5 \%$. The EAC considered that this was likely to be a significant over-estimate considering the impact of the recession since 2007

b 2011 NHS reference costs of ECG stated as $£ 31$

published literature [16, 22, 24, 25, 36] (Table 2). Annual and entry costs attributed to each health state were mainly derived from the NICE costing study Atrial Fibrillation [37], and adjusted upwards at an assumed rate of $5 \%$ per annum, since publication, to account for inflation. These values are presented in Table 3.
In the base-case analysis, the sponsor assumed that all patients would present to their GP with symptoms of AF and be tested for pulse irregularity with the WatchBP Home A or pulse palpation. Using an incidence estimate of $\mathrm{AF}$ of $0.175 \%$ derived from a NICE costing report [37], the sponsor calculated that 87,000 new cases of AF would 
present to primary care each year. The sponsor derived a prevalence rate of $4.4 \%$ from these data and a calculation taken from the SAFE study [16]. Overall, the sponsor found that detection of AF per se was associated with a net cost to the NHS, because the costs associated with detecting AF through ECG and subsequent anticoagulation management outweighed costs associated with preventing stroke. However, the sponsor calculated that the improved diagnostic accuracy of the WatchBP Home A would lead to an annual cost saving to the NHS of approximately $£ 11,600,000$, with the prevention of 221 strokes, when compared with pulse palpation. This cost saving resulted mainly from lower ECG costs associated with fewer FP tests.

The sponsor also performed a limited univariate and threshold sensitivity analysis based on a scenario where only a proportion of patients were symptomatic of AF. They found that if $50 \%$ of patients were asymptomatic then the WatchBP Home A was not cost saving. This was because time and ECG costs associated with pulse palpation were absent in $50 \%$ of patients simulated. The sponsor also performed a sensitivity analysis on the cost of stroke, by including societal costs. It was found that if an annual societal cost of stroke of $£ 44,000$ was assumed [38], the WatchBP Home A would result in annual savings of approximately $£ 64,600,000$ compared with $£ 45,400,000$ for pulse palpation. Threshold sensitivity analysis showed that an assumed annual cost of stroke of approximately $£ 16,000$ would result in savings for the WatchBP Home A.

\subsubsection{Critique of Economic Evidence}

The EAC identified several weaknesses in the sponsor's economic model, primarily relating to the fact that it did not match the scope of the decision problem, particularly in terms of model structure, the modelled population, the intervention and the comparator, and parameter inputs.

The EAC considered that the structure of the economic model was incorrect in that it derived important parameters in a reverse manner; i.e., it used the incidence data derived from different epidemiological studies together with diagnostic parameters taken from an RCT to inform about population prevalence $[16,36]$. From this, the number of people who would need to be screened to achieve this incidence was calculated. The EAC considered it would have been better to select and estimate the population consistent with the scope (i.e., people having a clinical measurement of BP), estimate the likely prevalence of AF in this population, and calculate forwards from this point, using sensitivity analyses as appropriate. An additional limitation of the sponsor's model was that it only had a time horizon of 1 year, which is insufficient to estimate the long-term implications of managing stroke risk (and likely to underestimate the benefits of the device).
The EAC considered that the population included in the model, people who are symptomatic of AF, was not the population described in the scope, and it should have been people who were having their BP measured (i.e., people asymptomatic of AF). The EAC considered this was a fundamental error in the sponsor's analysis, and noted that the sponsor's own sensitivity analysis indicated the WatchBP Home A was not cost saving in asymptomatic populations. Additionally, an important area of research described in the scope which the sponsor omitted from the model was the use of the WatchBP Home A for the diagnosis or monitoring of hypertension in a home setting (with the possible incidental detection of AF).

The EAC was asked to provide an analytic model of the device in a home setting. The EAC found that the WatchBP Home A was always cost-incurring in this setting, due to the lack of a suitable comparator and the fact that the costs of anticoagulation management outweighed those of preventing stroke.

The EAC did not fully agree with the sponsor's choice of study to inform the diagnostic accuracy of the WatchBP Home A and pulse palpation; these issues are presented in Table 2. Part of the claimed cost saving of the WatchBP Home A was that the device saved time compared with manual pulse palpation, but the EAC did not accept this was likely due to the repeat measurements required by the device's instructions for use. Additionally, the EAC noted that, according to the NICE processes and methods guides, cost estimates should be taken from the perspective of the NHS and PSS and not society as a whole (i.e., indirect costs should not be counted) [39], so the sponsor's use of societal costs for stroke in their sensitivity analysis fell outside the scope of the MTEP's processes and methods. Other issues with parameters and costs are presented in Table 3.

Overall, the EAC considered that there were significant uncertainties about the model structure, inputs and parameter. The Committee (MTAC) considered that the issues raised by the EAC were valid and therefore asked for further modelling to be carried out. The EAC developed a cost-consequence decision-analytic model, from the perspective of NHS and personal social care costs, to simulate incidental detection of asymptomatic AF in a primary-care population. The number of critical events (fatal and nonfatal strokes, gastro-intestinal bleeds) and accumulated costs for the WatchBP Home A were estimated and compared with manual pulse palpation for two age cohorts (65-74 and 75-84 years). The year of valuation was 2011 and the discount rate was $3.5 \%$. From this de novo model, the EAC estimated that the WatchBP Home A was associated with a per use saving of $£ 2.98$ for patients aged 65-74 years and $£ 4.26$ for people aged 75-84 years (potential savings in younger age groups could not be meaningfully quantified). Given the frequency that BP 
measurement is undertaken, this would represent significant savings for the NHS in England and Wales. Additionally, the device was associated with the prevention of 53-117 nonfatal and 28-65 fatal strokes over a 10-year time period, per 100,000 people measured, due to incidental detection of $\mathrm{AF}$ and subsequent prevention of stroke.

\section{NICE Guidance}

\subsection{Preliminary Guidance}

In July 2012, MTAC met and made the following provisional recommendations regarding the WatchBP Home A.

"1.1 The case for adopting "WatchBP Home A" in the NHS for measuring BP, with the additional aim of detecting asymptomatic atrial fibrillation, is supported by the evidence. The available evidence suggests that the device reliably detects atrial fibrillation and may increase the rate of detection when used in primary care. This would allow prophylactic treatment to be given to reduce the incidence of atrial fibrillation-related stroke."

"1.2 "WatchBP Home A" should be considered for use in people with suspected hypertension or those being screened for hypertension in primary care. People suspected of having atrial fibrillation after use of "WatchBP Home A" should have an electrocardiogram (ECG) in line with NICE clinical guideline 36, 'Atrial fibrillation'."

"1.3 Use of "WatchBP Home A" in primary care is associated with estimated overall cost savings per person screened ranging from $£ 2.98$ for those aged between 65 and 74 years to $£ 4.26$ for those aged 75 years and over. There is uncertainty about the costs and benefits for people under 65 years of age, however it is likely that using the device in this group will benefit patients and the healthcare system" [6].

\subsection{Consultation Response}

Following publication of the draft guidance on the NICE website, all stakeholders, including the general public, were invited to provide comment before the final guidance was released. In the case of the WatchBP Home A, only limited comments were received, which did not fundamentally challenge the provisional recommendations.

The lack of guidance for the potential use of the WatchBP Home A in a home setting was of concern to some commentators. This was a scenario that had been covered previously by the additional analysis conducted by the EAC, which showed that the device was always costexpending in this scenario, because management of detected AF was always more expensive than non-management in the EAC's model. However, due to the costconsequence methodology employed, this did not take into account the potential clinical and patient benefits of the device (for instance, in terms of patient utility and life expectancy) [35]. NICE clinical guidelines recommend ambulatory BP measurement to confirm a diagnosis of hypertension following a high clinic BP measurement [10]. There is no guidance on the use of oscillometric BP devices at home, and since there is no comparator, use of the WatchBP would be cost incurring. For these reasons, no guidance on the use of the device at home was given.

The final comment that required significant discussion related to extrapolating the results to the population aged under 65 years; younger populations were not modelled by the EAC due to technical limitations of the design employed and the available data used to populate the model. However, after consideration, the committee concluded that the device was almost certain to be of clinical benefit, and likely to be cost saving in the younger age group, and this was reflected in the final recommendations.

\section{Key Challenges and Learning Points}

A significant problem both the sponsor and the EAC faced was the complexity of the decision problem, which meant it was difficult to create a cost-consequence model that could accurately reflect the entire scope. Specific difficulties included the fact that two physiological parameters are simultaneously detected by the WatchBP Home A (BP indicative of hypertension, and irregular pulse indicative of $\mathrm{AF}$ ); there were two potential settings (clinic and home); $\mathrm{AF}$ itself is a complex condition (presenting as symptomatic, asymptomatic, paroxysmal, persistent and permanent [40]); and that both hypertension and $\mathrm{AF}$ require different technologies to confirm the respective diagnoses (ambulatory measurement preferred for hypertension [10] and 12-lead ECG for AF [12]). Additionally, and in common with all screening technologies, the WatchBP Home A does not directly treat either condition, but influences subsequent care; thus it is the patient pathway overall that is changed and requires modelling, which adds another level of complexity compared with a therapeutic intervention [41]. The primary benefit to patients claimed in the context of the WatchBP Home A is the prevention of thromboembolic stroke. However, this outcome may occur years or even decades after the WatchBP Home A has initially been used, which means decision-analytic models are the only realistic option to perform the required analyses. These models are associated with large inherent uncertainties and imprecision [42]. 
An additional problem was that the EAC considered that only one published study was of adequate relevance and quality to inform the economic model [25]. This was a cross-sectional diagnostic study which, whilst being of appropriate design to measure the sensitivity and specificity of the device in a particular clinical context, did not provide relevant clinical outcome data, as an RCT might. Additionally, the population described in the study (a secondary-care cardiology clinic in the USA) was at high risk of $\mathrm{AF}$ and not representative of the population described in the MTEP scope. Potential uncertainties concerning other parameter inputs are presented in Table 3. Thus, from the outset there were significant uncertainties concerning the external validity of the data used to populate the economic model, which needs to be considered when interpreting the recommendations, particularly in younger people at lower risk of AF. An estimate of residual uncertainty that derives from limited clinical evidence could be made using more sophisticated analytical techniques, for instance by using probabilistic Bayesian modelling rather than deterministic sensitivity analysis [43].

\section{Conclusion}

In conclusion, the WatchBP Home A has been subjected to the MTEP evaluation process, which includes the submission of clinical and economic evidence by the sponsor, critical appraisal of this evidence by the EAC, followed by the formulation of recommendations by MTAC. The sponsor's submission was not directly aligned with the statement of the decision problem, which added complexity to the critical appraisal process, and required additional economic modelling by the EAC before the Committee (MTAC) was convinced that the benefits of the device were sufficiently demonstrated for it to receive a positive recommendation in MTG13.

Disclosures Newcastle upon Tyne Hospitals and York Health Economics Consortium are funded by NICE to act as an EAC for the Medical Technologies Evaluation Programme. This summary of the Medical Technology Guidance was produced following publication of the final guidance report. This summary has been reviewed by NICE but has not been externally peer reviewed by Applied Health Economics and Health Policy. Three of the authors (IW, KK, AJS) are NHS employees; the NHS has a financial interest in the guidance issued by NICE as a result of this work.

Author contributions The manuscript was prepared by IW, with contributions from KK, JC and AS. The model was developed by KK and AS with advice and quality assurance by JC. The guarantor for overall content is AS.

Open Access This article is distributed under the terms of the Creative Commons Attribution Noncommercial License which permits any noncommercial use, distribution, and reproduction in any medium, provided the original author(s) and the source are credited.

\section{References}

1. Campbell B, Campbell M. NICE Medical Technologies Guidance: a novel and rigorous methodology to address a new health technology assessment challenge. Appl Health Econ Health Policy. 2012;10(5):295-7.

2. National Institute for Health and Care Excellence. Medical Technologies Evaluation Programme: Process Guide. 2011. http: //www.nice.org.uk/media/3A6/14/MedicalTechnologiesEvaluatio nProgrammeProcessGuideMarch2012.pdf. Last Accessed March 2014.

3. National Institute for Health and Care Excellence. Medical Technology Guidance 13: WatchBP Home A for opportunistically detecting atrial fibrillation during diagnosis and monitoring of hypertension. 2013. http://www.nice.org.uk/nicemedia/live/ 14020/62321/62321.pdf. Last Accessed March 2014.

4. White J, Carolan-Rees G. PleurX peritoneal catheter drainage system for vacuum-assisted drainage of treatment-resistant, recurrent malignant ascites. Appl Health Econ Health Policy. 2012;10(5):299-308.

5. Withers K, Carolan-Rees G, Dale M. Pipeline ${ }^{\mathrm{TM}}$ embolization device for the treatment of complex intracranial aneurysms. Appl Health Econ Health Policy. 2013;11(1):5-13.

6. National Institute for Health and Care Excellence. Medical Technology Guidance 145. 2011. http://guidance.nice.org.uk/ MT/145. Last Accessed March 2014.

7. Mancia G, Fagard R, Narkiewicz K, et al. 2013 ESH/ESC Guidelines for the management of arterial hypertension. J Hypterten. 2013;31:1281-357.

8. Lewington S, Clarke R, Qizilbash N, et al. Age-specific relevance of usual blood pressure to vascular mortality: a meta-analysis of individual data for one million adults in 61 prospective studies. Lancet. 2002;360:1903-13.

9. Healey JS, Connolly SJ. Atrial fibrillation: hypertension as a causative agent, risk factor for complications, and potential therapeutic target. Am J Cardiol. 2003;91(suppl):9G-14G.

10. National Institute for Health and Care Excellence. Clinical Guideline 127: hypertension: clinical management of primary hypertension in adults. 2011. http://www.nice.org.uk/nicemedia/ live/13561/56008/56008.pdf. Last Accessed March 2014.

11. Lévy S, Camm AJ, Saksena S, et al. International consensus on nomenclature and classification of atrial fibrillation: a collaborative project of the Working Group on Arrhythmias and the Working Group on Cardiac Pacing of the European Society of Cardiology and the North American Society of Pacing and Electrophysiology. Europace. 2003;5:119-22.

12. National Institute for Health and Care Excellence. Clinical Guideline 36: atrial fibrillation, National clinical guideline for management in primary and secondary care. 2006. http://www. nice.org.uk/nicemedia/live/10982/30055/30055.pdf. Last Accessed March 2014.

13. Benjamin EJ, Chen P, Bild DE, et al. Prevention of atrial fibrillation: Report from an NHLBI workshop. Circulation. 2009;119(4):606-18.

14. Quality and Outcomes Framework (QOF) database. 2012. http:// www.gpcontract.co.uk/browse/UK/Atrial\%20Fibrillation/12. Last Accessed March 2014.

15. Kannel WB, Wolf PA, Benjamin EJ, Levy D. Prevalence, incidence, prognosis, and predisposing conditions for atrial fibrillation: population-based estimates. Am J Cardiol. 1998;82:2N-9N.

16. Hobbs FDR, Fitzmaurice DA, Jowett $S$ et al. A randomised controlled trial and cost-effectiveness study of systematic screening (targeted and total population screening) versus routine practice for the detection of atrial fibrillation in people aged 65 
and over. The SAFE study. Health Technol Assess. 2005; 9(40):1-90.

17. Wolf PA, Abbott RD, Kannel WB. Atrial fibrillation as an independent risk factor for stroke: the Framingham Study. Stroke. 1991;22:983-8.

18. Benjamin EJ, Wolf PA, D'Agostino RB, et al. Impact of atrial fibrillation on the risk of death the Framingham Heart Study. Circulation. 1998;98:946-52.

19. Cooke G, Doust J, Sanders S. Is pulse palpation helpful in detecting atrial fibrillation? A systematic review. J Fam Pract. 2006;55(2):130-4.

20. Public Health England. NHS health check: our approach to the evidence. https://www.gov.uk/government/uploads/system/uploads /attachment_data/file/224537/NHS_Health_Check_our_approach_ to_the_evidence_v2.pdf. Last Accessed March 2014.

21. Stergiou GS, Giovas PP, Gkinos CP, Patouras JD. Validation of the Microlife WatchBP Home device for self home blood pressure measurement according to the International Protocol. Blood Press Monit. 2007;12:185-8.

22. Wiesel J, Wiesel D, Suri R, Messineo FC. The use of a modified sphygmomanometer to detect atrial fibrillation in outpatients. Pace. 2004;27:1-6.

23. Wiesel J, Wiesel DJ, Messineo FC. Home monitoring with a modified automatic sphygmomanometer to detect recurrent atrial fibrillation. J Stroke Cerebrovas Dis. 2007;16(1):8-13.

24. Stergiou GS, Karpettas N, Protogerou A, Nasothimiou EG, Kyriakidis M. Diagnostic accuracy of a home blood pressure monitor to detect atrial fibrillation. J Human Hypertens. 2009;23: 654-8.

25. Wiesel J, Fitzig L, Herschman Y, Messineo FC. Detection of atrial fibrillation using a modified microlife blood pressure monitor. Am J Hypertens. 2009;22(8):848-52.

26. Wiesel J, Abraham S, Messineo FC. Screening for asymptomatic atrial fibrillation while monitoring the blood pressure at home: trial of regular versus irregular pulse for prevention of stroke (TRIPPS 2.0). Am J Cardiol. 2013;111(11):1598-601.

27. Stergiou GS, Jaenecke B, Giovas PP, Chang A, Chung-Yueh Y, Tan TM. A tool for reliable self-home blood pressure monitoring designed according to the European Society of Hypertension recommendations: the Microlife WatchBP Home monitor. Blood Press Monit. 2007;12(2):127-31.

28. Chung Y, de Greeff A, Shennan A. Validation and compliance of a home monitoring device in pregnancy: microlife WatchBP home. Hypertens Pregnancy. 2009;28(3):348-59.

29. Wessel S, van der Hoeven NV, van den Born BJH, Cammenga M, van Montfrans GA. Microlife WatchBP for home blood pressure measurement more accurate in 'diagnostic' mode compared to usual mode. J Hypertens. 2010;28 (e-supplement):e454.

30. Kearley K, Selwood MP, Van den Bruel A et al. What is the best way to screen for atrial fibrillation in primary care? A comparison of the accuracy of 3 methods: nurse pulse palpation, a hand-held ECG and a modified BP monitor. 2010. http://www.in2health. org/wp-content/uploads/2013/09/What-is-the-best-way-to-screenfor-atrial-fibrillation-in-primary-care.pdf. Last Accessed March 2014.
31. Worster A, Carpenter C. Incorporation bias in studies of diagnostic tests: how to avoid being biased about bias. CJEM. 2008;10(2):174-5.

32. Critical Appraisal Skills Programme (CASP). http://www.caspuk.net/. Last Accessed March 2014.

33. Kelly S, Berry E, Roderick P. The identification of bias in studies of the diagnostic performance of imaging modalities. Br J Radiol. 1997;70:1028-35.

34. Altman DG, Bland JM. Diagnostic test 2: predictive values. BMJ. 1994;309(9):102.

35. Mauskopf JA, Paul JE, Grant DM, Stergachis A. The role of cost-consequence analysis in healthcare decision-making. PharmacoEconomics. 1998;13(3):277-88.

36. Morgan S, Mant D. Randomised trial of two approaches to screening for atrial fibrillation in UK general practice. Br J Gen Pract. 2002;52:373-80.

37. National Institute for Health and Care Excellence. Atrial fibrillation: the management of atrial fibrillation. Costing report. 2006 http://www.nice.org.uk/nicemedia/live/10982/30061/30061.pdf. Last Accessed March 2014.

38. Saka O, McGuire A, Wolfe C. Cost of stroke in the United Kingdom. Age Ageing. 2009;38:27-32.

39. National Institute for Health and Care Excellence. Medical Technologies Evaluation Programme: methods guide. 2011. http://www.nice.org.uk/media/3A6/09/MedicalTechnologiesEval uationProgrammeMethodsGuideMarch2012.pdf. Last Accessed March 2014.

40. Lip GYH, Tello-Montoliu A. Management of atrial fibrillation. Heart. 2006;92:1177-82.

41. Drummond MF, Sculpher MJ, Torrance GW, O'Brien BJ, Stoddart GL. Methods for the economic evaluation of health care programmes. New York: Oxford University Press; 2005.

42. Manning WG, Fryback DG, Weinstein MC. Refecting uncertainty in cost-effectiveness analysis. In: Gold MR, Siegel JE, Russel LB, Weinstein MC, editors. Cost-effectiveness in health and medicine. New York: Oxford University; 1996. p. 247-75.

43. Cooper NJ, Sutton AJ, Abrams KR. Decision analytical economic modelling within a Bayesian framework: application to prophylactic antibiotics use for caesarean section. Stat Methods Med Res. 2002;11(6):491-512.

44. Fitzmaurice DA, Hobbs FD, Jowett S, Mant J, Murray ET, Holder $\mathrm{R}$, et al. Screening versus routine practice in detection of atrial fibrillation in patients aged 65 or over: cluster randomised controlled trial. BMJ. 2007;335(7616):383.

45. Department of Health. 2009-10 reference costs publication. 2010. https://www.gov.uk/government/publications/nhs-reference-costs2009-2010. Last Accessed March 2014.

46. National Institute of Health and Care Excellence. NICE Technology appraisal guidance 249, 2012. Atrial fibrillation-dabigatran etexilate for the prevention of stroke and systemic embolism in atrial fibrillation. http://guidance.nice.org.uk/ TA249/Guidance/pdf/English. Last Accessed March 2014. 